\title{
Trends in mortality rates by subtypes of heart disease in Mississippi, 1980-2013
}

Vincent L. Mendy ${ }^{1 *}$, Rodolfo Vargas ${ }^{1}$ and Marinelle Payton ${ }^{2}$

\begin{abstract}
Background: Heart disease (HD) is the leading cause of death among Mississippians. However, trends in mortality rates for HD subtypes in Mississippi have not been adequately described. This study examined trends in mortality rates for HD subtypes among adults in Mississippi from 1980 through 2013.

Methods: We used Mississippi Vital Statistics data to calculate age-specific mortality rates for HD subtypes for Mississippians age 35 and older. Cases were identified via underlying cause of death codes from the International Classification of Diseases, Ninth Revision (ICD-9) and Tenth Revision (ICD-10). We used Joinpoint software to calculate the average annual percent change (AAPC) in mortality rates for HD subtypes by race, sex, and age group.

Results: Overall, the age-adjusted coronary heart disease (CHD) mortality rate among Mississippi adults decreased by 62.7\% between 1980 and 2013, with an AAPC of $-3.0 \%(95 \% \mathrm{Cl}-3.7$ to -2.3$)$, while the age-adjusted heart failure mortality rate increased by $66.7 \%$, with an AAPC of $1.4 \%$ ( $95 \% \mathrm{Cl} 0.5$ to 2.3$)$. Trends varied across HD subtypes: Annual rates of hypertensive HD mortality increased significantly for men, for individuals age 35 to 54, and for individuals age 75 and older. CHD mortality experienced a significant annual decrease among all race, sex, and age subgroups, while heart failure increased significantly among women, whites, and individuals age 75 and older.
\end{abstract}

Conclusions: From 1980 to 2013, CHD mortality decreased significantly while heart failure mortality increased significantly among adult Mississippians. However, HD subtype trends differed by race, sex, and age group.

Keywords: Average annual percent change, Heart disease subtypes, Mortality, Mississippi, Trends

\section{Background}

Heart disease (HD) is the leading cause of death among adults in the United States (U.S.) [1]. In 2013, the HD mortality rate in Mississippi was 1.4 times higher than the national rate [2]. HD accounted for a quarter of all deaths among Mississippi adults in 2013, and an even larger proportion of deaths among blacks and men in the state [3].

A recent national study indicated that HD mortality declined substantially among U.S. adults from 1973 and 2010, although the pattern of decline varied by race and geography [4]. Researchers have attributed these declines to both reductions in major risk factors for HD (e.g., cigarette smoking, hypertension, and hyperlipidemia) and the use of evidence-based medical and pharmaceutical

\footnotetext{
* Correspondence: vincent.mendy@msdh.ms.gov

${ }^{1}$ Office of Health Data and Research, Mississippi State Department of Health,

570 East Woodrow Wilson, Jackson, MS 39215, USA

Full list of author information is available at the end of the article
}

therapies that improve disease control (e.g., individuals with hypertension managing their blood pressure) $[5,6]$.

While there is extensive information on overall HD trends, there is a dearth of information on trends for HD subtypes, both nationally $[3,4,7]$ and in Mississippi. Specifically, there is limited information on trends in mortality rates for HD subtypes in Mississippi. To address this gap, we calculated the AAPC in age-adjusted mortality rates for HD subtypes among Mississippi adults ( $\geq 35$ years of age) between 1980 and 2013. In addition, we examined how AAPC varied by race, sex, and age group.

\section{Methods}

The number of adult ( $\geq 35$ years of age) deaths due to HD for each year from 1980 through 2013 were extracted from Mississippi Vital Statistics [3]. We used the underlying cause of death codes from the International Classification of Diseases, Ninth Revision (ICD-9) and Tenth Revision (ICD-10) for hypertensive HD [ICD-9:402; ICD- 
10:I11,I13], coronary heart disease (CHD) [ICD-9: 402, 410-414,429.2; ICD-10: I20-I25], and heart failure [ICD9:428; ICD-10: I50] [7]; ICD-9 was used for data from 1980 through 1999 and ICD-10 was used for data from later years. Other HD subtypes (acute rheumatic fever, chronic rheumatic heart disease, pulmonary heart disease) were not included because the data were insufficient. We then used Mississippi population census counts to calculate the age-adjusted HD mortality rates and standard errors for the state as a whole, for race subgroups (blacks, whites), and for gender subgroups (women, men). Ageadjustment was conducted via the direct method, based on the 2000 U.S. standard projected population [8].

Next, we exported age-adjusted mortality rates for HD subtypes and standard errors to the U.S. Surveillance, Epidemiology, and End Results (SEER) Joinpoint software (4.1.1.5) (http://surveillance.cancer.gov/joinpoint/) to calculate the AAPC in HD mortality rates by race, sex, and age group. Joinpoint regression analysis identifies trend breaks (joinpoints)-points of significant change in a trend $[7,9]$. This analysis identified time periods with statistically distinct log-linear trends in mortality rates for each HD subtype [9]. Using a Bayesian information criterion approach to select the most parsimonious model of best fit, we specified a maximum of three joinpoints [8-11]. The slopes of the models were used to calculate the average percentage change (APC) for each trend segment and the AAPC (the weighted average of the APC) [7]. For each AAPC, 95\% confidence intervals (CIs) were calculated and tested to determine whether the change was statistically significant (significantly different from the null hypothesis of no change, or $0 \%)[12,13]$ using a $p$-value of $<0.05$. This investigation was approved by the Mississippi State Department of Health Institutional Review Board.

\section{Results}

Overall, from 1980 through 2013, the age-adjusted CHD mortality rate decreased by $62.7 \%$, and the AAPC was $-3.0 \%$ (95\% CI -3.7 to -2.3$)$. For heart failure, the age-adjusted mortality rate increased by $66.7 \%$, and the AAPC was $1.4 \%$ (95\% CI 0.5 to 2.3 ).

Age-adjusted mortality rates for subtypes of HD varied by race, sex, and age group.

CHD mortality rates decreased significantly for all subgroups, with an AAPC of $-3.0 \%$ (95\% CI -3.6 to -2.3 ) for men, $-3.1 \%$ (95\% CI -3.6 to -2.5 ) for women, $-3.1 \%$ (95\% CI -3.4 to -2.7$)$ for whites, $-3.1 \%$ (95\% CI -4.2 to -2.0$)$ for blacks, $-1.5 \%(95 \% \mathrm{CI}-1.7$ to -1.2$)$ for individuals age $35-54,-3.0 \%$ (95\% CI -3.6 to -2.3 ) for individuals age $55-74$, and $-3.2 \%$ (95\% CI -3.7 to -2.8 ) for individuals age 75 and older.

In contrast, hypertensive HD mortality rates increased significantly among certain subgroups, with an AAPC of
1.6\% (95\% CI 0.3 to 3.0 ) for men, $4.5 \%$ (3.6 to 5.5 ) for individuals age $35-54$, and $1.4 \%$ (95\% CI 0.2 to 2.6 ) for individuals age 75 and older.

Heart failure mortality rates also increased significantly among certain subgroups, although a different set, with an AAPC of $1.8 \%$ (95\% CI 0.6 to 2.9 ) for women, 1.7\% (95\% CI 0.6 to 2.8 ) for whites, and $2.1 \%$ (95\% CI 0.9 to 3.3 ) for individuals age 75 and older (Table 1, Figs. 1, 2 and 3).

\section{Discussion}

Our analysis of mortality rates for subtypes of HD among Mississippians age 35 and older from 1980 to 2013 produced mixed results. Overall, the CHD mortality rate declined significantly, while the heart failure mortality rate increased significantly. The significant decline in CHD mortality in Mississippi mirrors findings from the Atherosclerosis Risk in Communities (ARIC) study, which includes the city of Jackson, Mississippi [14], as well as the findings of a recent national study [7]. However, we observed a significant increase in heart failure mortality among Mississippians, which differs from the national trend [7]. Although HD mortality rates have declined in recent years in Mississippi [15], HD remains the leading cause of death, with 8962 average deaths annually [3]. The results indicated that the decline in HD mortality in Mississippi was mainly due to a significant decrease in CHD mortality across all race, sex, and age subgroups. National declines in HD morality have been attributed to primary HD prevention, early diagnosis, and improved treatment [5, 6, 16-19].

The magnitude of decline in CHD mortality was comparable across all sex, race, and age subgroups, with the exception of individuals age 35-54, whose magnitude of decline was half that of the overall group. The continual decline in HD mortality in Mississippi can be largely attributed to the dramatic decline in CHD mortality among all Mississippians age 35 and older. The ubiquitous decline in CHD may be due to increased risk factor awareness, better control of risk factors, early diagnosis, and improved treatment $[5,16-22]$. Specifically, in a study of major risk factors in the 18-county Mississippi Delta region (a high cardiovascular disease burden region), we previously found that the prevalence of current smoking decreased significantly among white adults between 2001 and 2010 [23].

HD deaths attributable to hypertensive HD increased significantly among men, individuals age 35 to 54 , and individuals age 75 and older during this focal period; the largest magnitude of increase occurred among those 35 to 54 years old. These increases may be due to an increasing prevalence of obesity and diabetes [24]. In 2013, Mississippi had the highest prevalence of adult obesity (35.1\%) and second highest diabetes prevalence (12.9\%) [25]. In addition, Mississippi adults have poor cardiovascular health $[26,27]$. 
Table 1 Trends in Mortality Rates among Mississippi Adults 35 years and older by Heart Disease Subtype, 1980-2013

\begin{tabular}{|c|c|c|c|c|c|c|c|c|c|c|}
\hline \multirow{2}{*}{ HD Subtype ${ }^{a}$} & \multirow[b]{2}{*}{ Trend } & \multirow[b]{2}{*}{ Year } & \multirow[b]{2}{*}{ Total } & \multicolumn{2}{|l|}{ Sex } & \multicolumn{2}{|l|}{ Race } & \multicolumn{3}{|c|}{ Age Group, years } \\
\hline & & & & $\overline{\text { Men }}$ & Woman & White & Black & $35-54$ & $55-74$ & $\geq 75$ \\
\hline \multirow[t]{6}{*}{ Hypertensive } & \multirow{4}{*}{$\begin{array}{l}\text { Deaths, No. (rate/ } \\
100,000)^{b}\end{array}$} & 1980 & 350 & 156 & 194 & 155 & 195 & 19 & 146 & 185 \\
\hline & & & (33.2) & (35.5) & (31.3) & $(22.2)$ & $(58.2)$ & (3.9) & (36.9) & $(168.0)$ \\
\hline & & 2013 & 864 & 410 & 454 & 450 & 410 & 112 & 282 & 470 \\
\hline & & & $(54.8)$ & $(59.4)$ & $(50.0)$ & (39.5) & (93.9) & $(15.0)$ & $(47.1)$ & (270.8) \\
\hline & \multirow[t]{2}{*}{ AAPC $(95 \% \mathrm{Cl})$} & & 1.6 & $1.6^{c}$ & 1.5 & 2.0 & 1.2 & $4.5^{\mathrm{c}}$ & 0.9 & $1.4^{c}$ \\
\hline & & & $(-1.3,4.5)$ & $(0.3,3.0)$ & $(-1.0,4.0)$ & $(-0.7,4.7)$ & $(-1.8,4.4)$ & $(3.6,5.5)$ & $(-0.5,2.2)$ & $(0.2,2.6)$ \\
\hline \multirow{6}{*}{$\begin{array}{l}\text { Coronary Heart } \\
\text { Disease }\end{array}$} & \multirow{4}{*}{$\begin{array}{l}\text { Deaths, No. (rate/ } \\
100,000)\end{array}$} & 1980 & 6561 & 3565 & 2996 & 4569 & 1983 & 470 & 2704 & 3387 \\
\hline & & & $(624.0)$ & (810.6) & $(482.7)$ & $(637.0)$ & (600.6) & (95.9) & $(683.7)$ & (3075.1) \\
\hline & & 2013 & 3750 & 2200 & 1550 & 2674 & 1050 & 441 & 1507 & 1802 \\
\hline & & & $(232.5)$ & (313.1) & (168.0) & $(230.8)$ & $(227.7)$ & $(59.0)$ & $(251.9)$ & (1038.3) \\
\hline & \multirow[t]{2}{*}{ AAPC $(95 \%$ Cl) } & & $-3.0^{c}$ & $-3.0^{c}$ & $-3.1^{c}$ & $-3.1^{c}$ & $-3.1^{c}$ & $-1.5^{c}$ & $-3.0^{c}$ & $-3.2^{c}$ \\
\hline & & & $(-3.7,-2.3)$ & $(-3.6,-2.3)$ & $(-3.6,-2.5)$ & $(-3.4,-2.7)$ & $(-4.2,-2.0)$ & $(-1.7,-1.2)$ & $(-3.6,-2.3)$ & $(-3.7,-2.8$ \\
\hline \multirow[t]{6}{*}{ Heart Failure } & \multirow{4}{*}{$\begin{array}{l}\text { Deaths, No. (rate/ } \\
100,000 \text { ) }\end{array}$} & 1980 & 521 & 260 & 261 & 314 & 207 & 43 & 166 & 312 \\
\hline & & & $(51.1)$ & $(62.6)$ & $(43.1)$ & $(45.4)$ & $(65.0)$ & (8.8) & $(42.0)$ & $(283.3)$ \\
\hline & & 2013 & 1323 & 573 & 750 & 975 & 342 & 51 & 296 & 976 \\
\hline & & & $(85.2)$ & $(88.3)$ & $(81.8)$ & (84.6) & $(82.2)$ & (6.8) & $(49.5)$ & $(562.4)$ \\
\hline & \multirow[t]{2}{*}{$\operatorname{AAPC}(95 \% \mathrm{Cl})$} & & $1.4^{c}$ & 1.0 & $1.8^{c}$ & $1.7^{c}$ & 0.5 & 0.1 & -0.1 & $2.1^{c}$ \\
\hline & & & $(0.5,2.3)$ & $(0.0,2.0)$ & $(0.6,2.9)$ & $(0.6,2.8)$ & $(-1.1,2.2)$ & $(-1.6,1.9)$ & $(-1.6,1.3)$ & $(0.9,3.3)$ \\
\hline
\end{tabular}

AAPC, average annual percent change; $\mathrm{Cl}$, confidence interval

${ }^{a}$ The table provides the international Classification of Diseases (ICD), Ninth and Tenth Revisions, for each HD Subtype

${ }^{\mathrm{b}}$ Age adjusted using the 2000 U.S. standard population

'The AAPC is significantly different from zero

Coronary Heart Disease, ICD-9: 402, 410-414, 429.2 and ICD-10:120-125

Hypertensive HD, ICD-9:402 and ICD-10: I11, I13

Heart Failure, ICD-9:428 and ICD-10:150

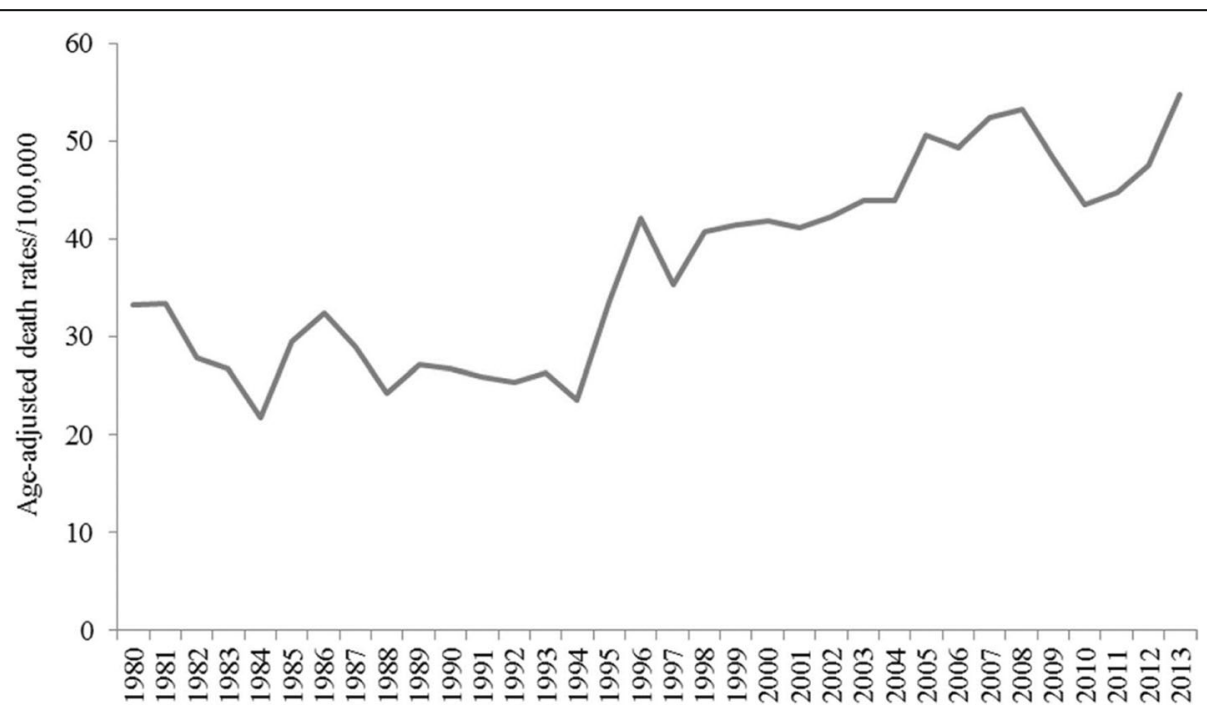

Fig. 1 Trends in age-adjusted hypertensive heart disease mortality rates among Mississippians 35 years and older, 1980-2013 


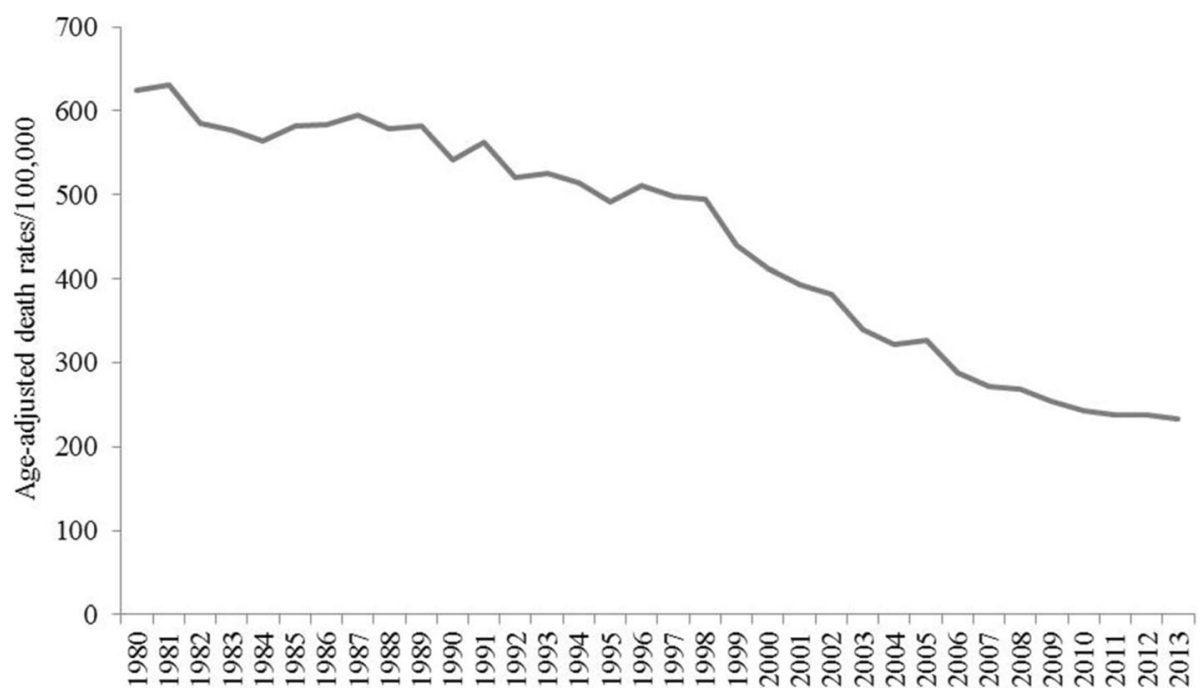

Fig. 2 Trends in age-adjusted coronary heart disease mortality rates among Mississippians 35 years and older, 1980-2013

For heart failure mortality, we observed significant increases among women, whites, and individuals age 75 and older. Heart failure mortality increases among these populations may be due to an increase in the number of adults aged 75 and older, and a higher prevalence of obesity and diabetes $[5,28]$. For example, the proportion of Mississippians 65 years and older grew from 11.5\% in 1980 to $13.9 \%$ in 2013 [3], and in the 18-county Mississippi Delta region (the northwestern portion of the state) the prevalence of obesity and diabetes increased significantly from 2001 to 2010 [23].

These findings have potential limitations. First, reliance on death certificates may introduce bias due to the misclassification of either the primary cause of death $[29,30]$ or the decedent's race [31], which can impact the conclusions drawn from epidemical studies [32]. However, death certificates are the only data source currently available to assess population trends in heart disease mortality (although they can be problematic if their accuracy varies over time) [30], and they allow the description of patterns in the entire population rather than a sample [33]. Second, changes in coding from ICD-9 to ICD-10 may affect the quality of death certificate data; however, a previous study validated the comparability of ICD-9 and ICD-10 in the analysis of mortality trends [34]. Finally, findings from a study of CHD deaths in New York City hospitals showed that CHD was overreported as a cause of death on death certificates [35]; if this also occurred in Mississippi hospitals, the CHD mortality rates calculated in the current study would be

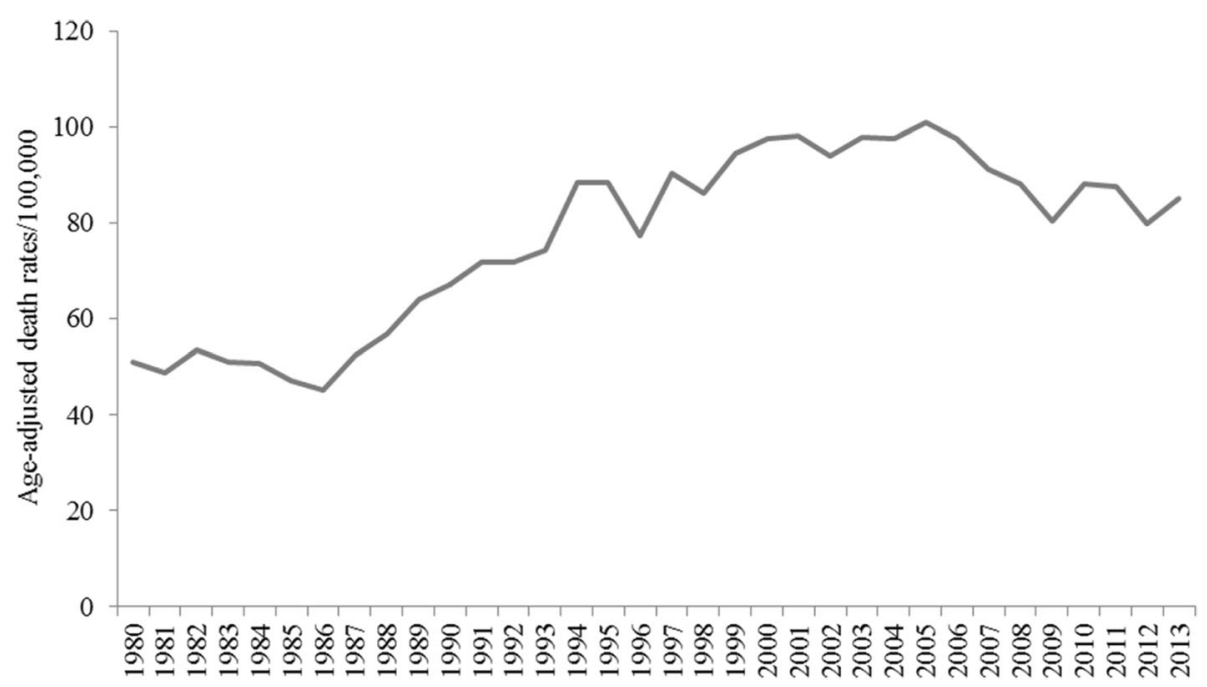

Fig. 3 Trends in age-adjusted heart failure mortality rates among Mississippians 35 years and older, 1980-2013 
biased. The extensive period of study and the analysis of population subgroups are key strengths of the study.

\section{Conclusions}

In conclusion, from 1980 through 2013, overall CHD mortality rates experienced significant annual declines, while heart failure mortality increased significantly among Mississippi adults age 35 and older. The significant decline in deaths due to CHD observed in all race, sex, and age subgroups in Mississippi during this period is noteworthy. Hypertensive HD mortality increased significantly among men, those 35 to 54 years old, and individuals age 75 and older, while heart failure mortality increased significantly for whites, women, and individuals age 75 and older.

Ongoing state public health actions to prevent and control diabetes, heart disease, obesity and associated risk factors and promote school health in partnership in local stakeholders include interventions that seek to improve health, including reducing death and disabilities due to heart disease (www.cdc.gov/chronicdisease/ about/state-public-health-actions.htm) [36]. In addition, in the 18-county Mississippi Delta region, the Mississippi State Department of Health, through the Mississippi Delta Health Collaborative (MDHC) and in collaboration with the Centers for Disease Control and Prevention (CDC) and local stakeholders, is currently implementing programs that aim to prevent and reduce heart disease, stroke, and associated risk factors, with a focus on the ABCS (aspirin for those at risk, blood pressure control, cholesterol management, and smoking cessation) of heart disease and stroke prevention (www.healthyms.com/MDHC).

\section{Abbreviations \\ AAPC: Average annual percent change; CHD: Coronary heart disease; $\mathrm{Cl}$ : Confidence interval; HD: Heart disease; ICD: International Classification of Diseases; MDHC: Mississippi Delta Health Collaborative}

\section{Acknowledgements}

We sincerely thank Cassandra Dove, Dr. Victor Sutton, Dr. Lei Zhang, Dr. Mary Currier and Dick Johnson of the Mississippi State Department of Health.

\section{Funding}

Research reported in this publication was supported by the Centers for Disease Control and Prevention grant no. 5U50DP003088-04 and by National Institute On Minority Health And Health Disparities of the National Institutes of Health under Award Number P20MD006899.

\section{Availability of data and materials}

Request and permission to use the Mississippi Vital Statistics data require approval of the Mississippi State Department of Health (MSDH) Institutional Review Board (IRB). MSDH IRB application, research proposals and all other required documents should be submitted to the IRB at irb@msdh.ms.gov.

\section{Authors' contributions}

VLM conceived the study, contributed to its design and drafted the manuscript. RV contributed to the study design and performed the analysis. MP contributed to the study design and critically reviewed daft versions. All authors read and approved the final manuscript.

\section{Competing interests}

The authors declare that they have no competing interests.
Consent for publication

Not applicable.

Ethics approval and consent to participate

This study was approved by the Mississippi State Department of Health Institutional Review Board.

\section{Publisher's Note}

Springer Nature remains neutral with regard to jurisdictional claims in published maps and institutional affiliations.

\section{Author details}

'Office of Health Data and Research, Mississippi State Department of Health, 570 East Woodrow Wilson, Jackson, MS 39215, USA. ${ }^{2}$ Center of Excellence in Minority Health and Health Disparities, Institute of Epidemiology and Health Services Research, School of Public Health, Jackson State University, Jackson, USA.

Received: 17 October 2016 Accepted: 7 June 2017

Published online: 15 June 2017

\section{References}

1. Mozaffarian D, Benjamin EJ, Go AS, Arnett DK, Blaha MJ, Cushman M, Das SR, de Ferranti S, Després JP, Fullerton HJ, Howard VJ, Huffman MD, Isasi CR, Jiménez MC, Judd SE, Kissela BM, Lichtman JH, Lisabeth LD, Liu S, Mackey RH, Magid DJ, McGuire DK, Mohler ER 3rd, Moy CS, Muntner P, Mussolino ME, Nasir K, Neumar RW, Nichol G, Palaniappan L, Pandey DK, Reeves MJ, Rodriguez CJ, Rosamond W, Sorlie PD, Stein J, Towfighi A, Turan TN, Virani SS, Woo D, Yeh RW, Turner MB; American Heart Association Statistics Committee; Stroke Statistics Subcommittee. Heart Disease and Stroke Statistics-2016 Update: A Report From the American Heart Association. Circulation. 2016;133(4):e38-360.

2. Centers for Disease Control and Prevention, National Center for Health Statistics. Underlying Cause of Death 1999-2014 on CDC WONDER Online Database, released. Data are from the Multiple Cause of Death Files, 19992014, as compiled from data provided by the 57 vital statistics jurisdictions through the Vital Statistics Cooperative Program. 2015; https://wonder.cdc. gov. Accessed 24 Apr 2015

3. Mississippi Vital Statistics (The Mississippi STatistically Automated Health Resource System (MSTAHRS), 2013. http://mstahrs.msdh.ms.gov/. Accessed 23 Apr 2015.

4. Vaughan AS, Quick H, Pathak EB, Kramer MR, Casper M. Disparities in Temporal and Geographic Patterns of Declining Heart Disease Mortality by Race and Sex in the United States, 1973-2010. J Am Heart Assoc. 2015;4(12).

5. Ford ES, Ajani UA, Croft JB, Critchley JA, Labarthe DR, Kottke TE, et al. Explaining the decrease in U.S. deaths from coronary disease, 1980-2000. N Engl J Med. 2007;356(23):2388-98.

6. Decline in deaths from heart disease and stroke-United States. 1900-1999. MMWR Morb Mortal Wkly Rep. 1999;48(30):649-56.

7. Ritchey MD, Loustalot F, Bowman BA, Hong Y. Trends in mortality rates by subtypes of heart disease in the United States, 2000-2010. JAMA. 2014; 312(19):2037-9.

8. Berg J, Björck L, Lappas G, O'Flaherty M, Capewell S, Rosengren A. Continuing decrease in coronary heart disease mortality in Sweden. BMC Cardiovasc Disord. 2014:14:9.

9. Nichols M, Townsend N, Scarborough P, Rayner M. Trends in age-specific coronary heart disease mortality in the European Union over three decades: 1980-2009. Eur Heart J. 2013;34(39):3017-27.

10. O'flaherty M, Ford E, Allender S, Scarborough P, Capewell S. Coronary heart disease trends in England and Wales from 1984 to 2004: concealed levelling of mortality rates among young adults. Heart. 2008;94(2):178-81.

11. Edwards BK, Noone AM, Mariotto AB, Simard EP, Boscoe FP, Henley SJ, et al. Annual report to the nation on the status of cancer, 1975-2010, featuring prevalence of comorbidity and impact on survival among persons with lung, colorectal, breast, or prostate cancer. Cancer. 2014;120(9):1290-314.

12. Cayuela A, Rodríquez-Domínguez S, López-Campos JL, Otero Candelera R, Rodríguez MC. Joinpoint regression analysis of lung cancer mortality, Andalusia 1975-2000. Ann Oncol. 2004;15(5):793-6.

13. Qiu D, Katanoda K, Marugame T, Sobue T. A joinpoint regression analysis of long-term trends in cancer mortality in Japan (1958-2004). Int J Cancer. 2009;124(2):443-8. 
14. Rosamond WD, Chambless LE, Heiss G, Mosley TH, Coresh J, Whitsel E, et al. Twenty-two-year trends in incidence of myocardial infarction, coronary heart disease mortality, and case fatality in 4 US communities, 1987-2008. Circulation. 2012;125(15):1848-57.

15. Mendy VL, Vargas R, El-sadek L. Trends in heart disease mortality among Mississippi adults over three decades, 1980-2013. PLoS One. 2016;11(8):e0161194.

16. Wijeysundera HC, Machado M, Farahati F, Wang X, Witteman W, van der Velde $\mathrm{G}$, et al. Association of temporal trends in risk factors and treatment uptake with coronary heart disease mortality, 1994-2005. JAMA. 2010;303(18):1841-7.

17. Kones R. Primary prevention of coronary heart disease: integration of new data, evolving views, revised goals, and role of rosuvastatin in management. A comprehensive survey. Drug Des Devel Ther. 2011;5:325-80.

18. Ford ES, Capewell S. Proportion of the decline in cardiovascular mortality disease due to prevention versus treatment: public health versus clinical care. Annu Rev Public Health. 2011:32:5-22.

19. Roger VL, Weston SA, Gerber Y, Killian JM, Dunlay SM, Jaffe AS, et al. Trends in incidence, severity, and outcome of hospitalized myocardial infarction. Circulation. 2010;121(7):863-9.

20. Brown JR, O'connor GT. Coronary heart disease and prevention in the United States. N Engl J Med. 2010;362(23):2150-3.

21. Malach M, Imperato PJ. Acute myocardial infarction and acute coronary syndrome: then and now (1950-2005). Prev Cardiol. 2006;9(4):228-34.

22. Mosca L, Hammond G, Mochari-greenberger H, Towfighi A. Albert MA; American Heart Association cardiovascular disease and stroke in women and special populations Committee of the Council on clinical cardiology, Council on Epidemiology and prevention, Council on cardiovascular nursing, Council on high Bloo. Fifteen-year trends in awareness of heart disease in women: results of a 2012 American Heart Association national survey. Circulation. 2013;127(11):1254-63. e1-29

23. Mendy VL, Vargas R. Trends in major risk factors for cardiovascular disease among adults in the Mississippi Delta region, Mississippi behavioral risk factor Surveillance System, 2001-2010. Prev Chronic Dis. 2015;12:E21.

24. Smith CY, Bailey KR, Emerson JA, Nemetz PN, Roger VL, Palumbo PJ, Edwards WD, Leibson CL. Contributions of increasing obesity and diabetes to slowing decline in subclinical coronary artery disease. J Am Heart Assoc. 2015;4(4).

25. Centers for Disease Control and Prevention, National Center for Chronic Disease Prevention and Health Promotion, Division of Population Health BRFSS Prevalence \& Trends Data [online]. 2015. https:/www.cdc.gov/brfss/ index.html. Accessed 18 Jul 2016.

26. Short VL, Gamble A, Mendy V. Racial differences in ideal cardiovascular health metrics among Mississippi adults, 2009 Mississippi behavioral risk factor Surveillance System. Prev Chronic Dis. 2013;10:E194.

27. Fang J, Yang Q, Hong Y, Loustalot F. Status of cardiovascular health among adult Americans in the 50 States and the District of Columbia, 2009. J Am Heart Assoc. 2012;1(6):e005371.

28. Stewart S, Macintyre K, Capewell S, McMurray JJ. Heart failure and the aging population: an increasing burden in the 21st century? Heart. 2003;89(1):49-53.

29. Wexelman BA, Eden E, Rose KM. Survey of new York City resident physicians on cause-of-death reporting, 2010. Prev Chronic Dis. 2013;10:120288.

30. Gerber Y, Jacobsen SJ, Frye RL, Weston SA, Killian JM, Roger VL. Secular trends in deaths from cardiovascular diseases: a 25-year community study. Circulation. 2006;113(19):2285-92.

31. Horner RD, Day GM, Lanier AP, Provost EM, Hamel RD, Trimble BA. Stroke mortality among Alaska native people. Am J Public Health. 2009;99(11):1996-2000.

32. Harriss LR, Ajani AE, Hunt D, Shaw J, Chambers B, Dewey H, et al. Accuracy of national mortality codes in identifying adjudicated cardiovascular deaths. Aust N Z J Public Health. 2011;35(5):466-76.

33. Cohen J, Bilsen J, Miccinesi G, Löfmark R, Addington-Hall J, Kaasa S, et al. Using death certificate data to study place of death in 9 European countries: opportunities and weaknesses. BMC Public Health. 2007;7:283.

34. Anderson RN, Miniño AM, Hoyert DL, Rosenberg HM. Comparability of cause of death between ICD-9 and ICD-10: preliminary estimates. Natl Vital Stat Rep. 2001;49(2):1-32.

35. Agarwal R, Norton JM, Konty K, Zimmerman R, Glover M, Lekiachvili A, et al. Overreporting of deaths from coronary heart disease in new York City hospitals, 2003. Prev Chronic Dis. 2010;7(3):A47.

36. State Public Health Actions to Prevent and Control Diabetes, Heart Disease, Obesity and Associated Risk Factors and Promote School Health (DP13-1305). http://www.cdc.gov/chronicdisease/about/state-public-health-actions.htm. Accessed Jul 2016.

\section{Submit your next manuscript to BioMed Central and we will help you at every step:}

- We accept pre-submission inquiries

- Our selector tool helps you to find the most relevant journal

- We provide round the clock customer support

- Convenient online submission

- Thorough peer review

- Inclusion in PubMed and all major indexing services

- Maximum visibility for your research

Submit your manuscript at www.biomedcentral.com/submit
C Biomed Central 